\title{
BMJ Global Health Delivering nutrition interventions to women and children in conflict settings: a systematic review
}

\author{
Shailja Shah (D) , ${ }^{1}$ Zahra Ali Padhani (D) , ${ }^{2}$ Daina Als, ${ }^{1}$ Mariella Munyuzangabo, ${ }^{1}$ \\ Michelle F Gaffey, ${ }^{1}$ Wardah Ahmed, ${ }^{2}$ Fahad J Siddiqui, ${ }^{1,3}$ Sarah Meteke, ${ }^{1}$ \\ Mahdis Kamali, ${ }^{1}$ Reena P Jain (D) , ${ }^{1}$ Amruta Radhakrishnan, ${ }^{1}$ Anushka Ataullahjan, ${ }^{1}$ \\ Jai K Das, ${ }^{2}$ Zulfiqar A Bhutta ${ }^{1}$
}

\begin{abstract}
To cite: Shah S, Padhani ZA, Als D, et al. Delivering nutrition interventions to women and children in conflict settings: a systematic review. BMJ Global Health 2021;6:e004897. doi:10.1136/ bmjgh-2020-004897
\end{abstract}

Handling editor Seye Abimbola

- Additional material is published online only. To view, please visit the journal online (http://dx.doi.org/10.1136/ bmjgh-2020-004897).

SS and ZAP are joint first authors.

Received 29 December 2020 Revised 19 February 2021 Accepted 20 March 2021

A Check for updates

(C) Author(s) (or their employer(s)) 2021. Re-use permitted under CC BY. Published by BMJ.

${ }^{1}$ Centre for Global Child Health, Hospital for Sick Children, Toronto, Ontario, Canada ${ }^{2}$ Division of Women and Child Health, Aga Khan University, Karachi, Pakistan

${ }^{3}$ Health Services and Systems Research, Duke-NUS Graduate Medical School, Singapore

Correspondence to Dr Zulfiqar A Bhutta; Zulfiqar.bhutta@sickkids.ca

\section{ABSTRACT}

Background Low/middle-income countries (LMICs) face triple burden of malnutrition associated with infectious diseases, and non-communicable diseases. This review aims to synthesise the available data on the delivery, coverage, and effectiveness of the nutrition programmes for conflict affected women and children living in LMICs. Methods We searched MEDLINE, Embase, CINAHL, and PsycINF0 databases and grey literature using terms related to conflict, population, and nutrition. We searched studies on women and children receiving nutritionspecific interventions during or within five years of a conflict in LMICs. We extracted information on population, intervention, and delivery characteristics, as well as delivery barriers and facilitators. Data on intervention coverage and effectiveness were tabulated, but no metaanalysis was conducted.

Results Ninety-one pubblications met our inclusion criteria. Nearly half of the publications $(n=43)$ included population of sub-Saharan Africa $(n=31)$ followed by Middle East and North African region. Most publications $(n=58)$ reported on interventions targeting children under 5 years of age, and pregnant and lactating women $(n=27)$. General food distribution $(n=34)$, micronutrient supplementation $(n=27)$ and nutrition assessment $(n=26)$ were the most frequently reported interventions, with most reporting on intervention delivery to refugee populations in camp settings ( $n=63$ ) and using community-based approaches. Only eight studies reported on coverage and effectiveness of intervention. Key delivery facilitators included community advocacy and social mobilisation, effective monitoring and the integration of nutrition, and other sectoral interventions and services, and barriers included insufficient resources, nutritional commodity shortages, security concerns, poor reporting, limited cooperation, and difficulty accessing and following-up of beneficiaries.

Discussion Despite the focus on nutrition in conflict settings, our review highlights important information gaps. Moreover, there is very little information on coverage or effectiveness of nutrition interventions; more rigorous evaluation of effectiveness and delivery approaches is needed, including outside of camps and for preventive as well as curative nutrition interventions.

PROSPERO registration number CRD42019125221.

\section{Key questions}

What is already known?

- Women and children affected by conflict suffer from high burden of malnutrition and poor nutritional outcomes.

- In recent decades, conflict related deaths resulting from malnutrition and other health problems have increased significantly to the extent where they are now being considered a public health problem.

What are the new findings?

- General food distribution was the most common intervention provided in the included studies.

- Most of the intervention were delivered to refugee populations in camp settings and through community-based approaches.

- Very few studies reported on coverage and effectiveness of the nutritional interventions.

- Key delivery facilitators included community advocacy and social mobilisation, effective monitoring and the integration of nutrition and other sectoral interventions and services.

- Key delivery barriers included insufficient resources nutritional commodity shortages, security concerns, poor outcome reporting, limited cooperation and difficulty accessing and following-up of beneficiaries.

What do the new findings imply?

- Studies and research should be conducted to generate and strengthen evidence on coverage, access and improvement in delivery of nutritional interventions in context to conflict setting with rigorous and improved assessment methods.

- Studies should also study on multi-sectoral programming approach and its integration with early childhood development and mental health, which is an emerging issue.

\section{INTRODUCTION}

Armed conflict is defined as 'a political conflict in which armed combat involves the armed forces of at least one state (or one or more armed factions seeking to gain control 
of all or part of the state), and in which people have been killed by the fighting during the course of the conflict'. ${ }^{1}$ It originates due to social, individual and cultural differences, which leads to poverty, violence, malnutrition and mortality. ${ }^{2}$

Globally, 136 million people are in need of assistance due to conflict, while 52 million children suffer from acute malnutrition where disease epidemics are a global threat. ${ }^{3}{ }^{4}$ Low/middle-income countries (LMICs) face triple burden of malnutrition, ${ }^{5}$ which is more complicated where there is increase in protracted and recidivist conflict, population displacement and urban warfare. ${ }^{6}$

According to a recent systematic review by Blanchet et $a l^{7}{ }^{7}$ several nutritional programmes have been implemented by humanitarian organisations to aid vulnerable populations during emergency settings. ${ }^{8}$ According to recent Sphere guidance, although food insecurity is one cause of malnutrition, providing food assistance to vulnerable population is unlikely to contribute to a long lasting solution. ${ }^{9}$ Thus, a multi-sectoral approach to food and nutrition response in conflict settings has been advocated. Successful nutrition interventions in non-conflict nutrition settings are characterised by a combination of political commitment, multi-sectoral collaboration, community engagement, community-based service delivery platform, and wider programme coverage and compliance. ${ }^{10}$ In conflict settings, consensus on specific guidelines uptake is still obscure, hence, stronger scientific evidence of implementing effective nutrition interventions is required.

In this review we aimed to synthesise the data and information currently available on how nutrition interventions for women and children have been delivered in conflict settings, and the reported barriers and facilitators of programme delivery. We also aimed to synthesise the available data on the coverage of nutrition programmes for women and children in such settings and their effectiveness.

\section{METHODS}

This systematic review on nutritional interventions is a part of series of reviews in conflict settings which includes delivery of mental health, sexual and reproductive health and other interventions in conflict settings. ${ }^{11-18}$ This review adheres to the Preferred Reporting Items for Systematic Reviews and Meta-Analyses statement (online supplemental appendix 1), ${ }^{19}$ and its protocol is registered with PROSPERO (the international prospective register of systematic reviews, www.crd.york.ac.uk/prospero/).

\section{Search strategy and selection criteria}

We systematically searched MEDLINE, Embase, CINAHL and PsycINFO online databases for indexed journal articles published between 1 January 1990 and 31 March 2018 using search terms relating to women, children or adolescents accessing or receiving nutrition-specific interventions in conflict or post-conflict settings in LMICs (online supplemental appendix 2). In addition to the indexed literature, we also searched grey literature published between 1 January 2013 and 30 November 2018 on the websites of 10 major humanitarian organisations who are actively involved in responding to or researching conflict situations: Emergency Nutrition Network, International Committee of the Red Cross, International Rescue Committee, Médecins Sans Frontières, Save the Children, United Nations Population Fund, United Nations High Commissioner for Refugees, UNICEF, Women's Refugee Commission and World Vision. We used broad terms for conflict and health interventions tailored to the search functionality of each website.

We deduplicated all retrieved indexed records using Endnote X7 software, ${ }^{20}$ and then imported unique records into Covidence software, ${ }^{21}$ where two reviewers independently conducted screening of each title and/or abstract for relevance. Discrepancies between reviewers' decisions were resolved via discussion, or by a third reviewer if necessary. A single reviewer then assessed the full text of each potentially relevant publication to determine eligibility for the review. An eligible publication needed to describe a nutrition-specific intervention being delivered during or within five years of cessation of armed conflict to neonates, children, adolescents or women of reproductive age. Same approach was used for assessing grey literature.

For both indexed and grey literature, we excluded case reports of single patients; studies reporting on military personnel, refugee populations in high-income countries, surgical techniques or economic or mathematical modelling; editorials and opinion pieces; guidelines; and reviews.

\section{Data extraction}

We extracted relevant qualitative and quantitative information from eligible publications using a structured, pilot tested data abstraction tool in REDCap software in duplicate. ${ }^{22}$ Discrepancies between reviewers' data were resolved via discussion, or by a third reviewer if necessary.

\section{Data analysis and synthesis}

We descriptively analysed the key characteristics of the included publications, focal populations and reported interventions, including their delivery characteristics, and we tabulated reported estimates of intervention coverage and effectiveness. We compared reported nutrition treatment intervention coverage and effectiveness estimates with key indicators outlined in the Sphere Handbook ${ }^{9}$ of minimum standards in humanitarian response. We narratively synthesised information on delivery barriers and facilitators retrieved from our included publications. The effectiveness measures included the proportions of those discharged from a malnutrition treatment programme who recovered, defaulted or died. 


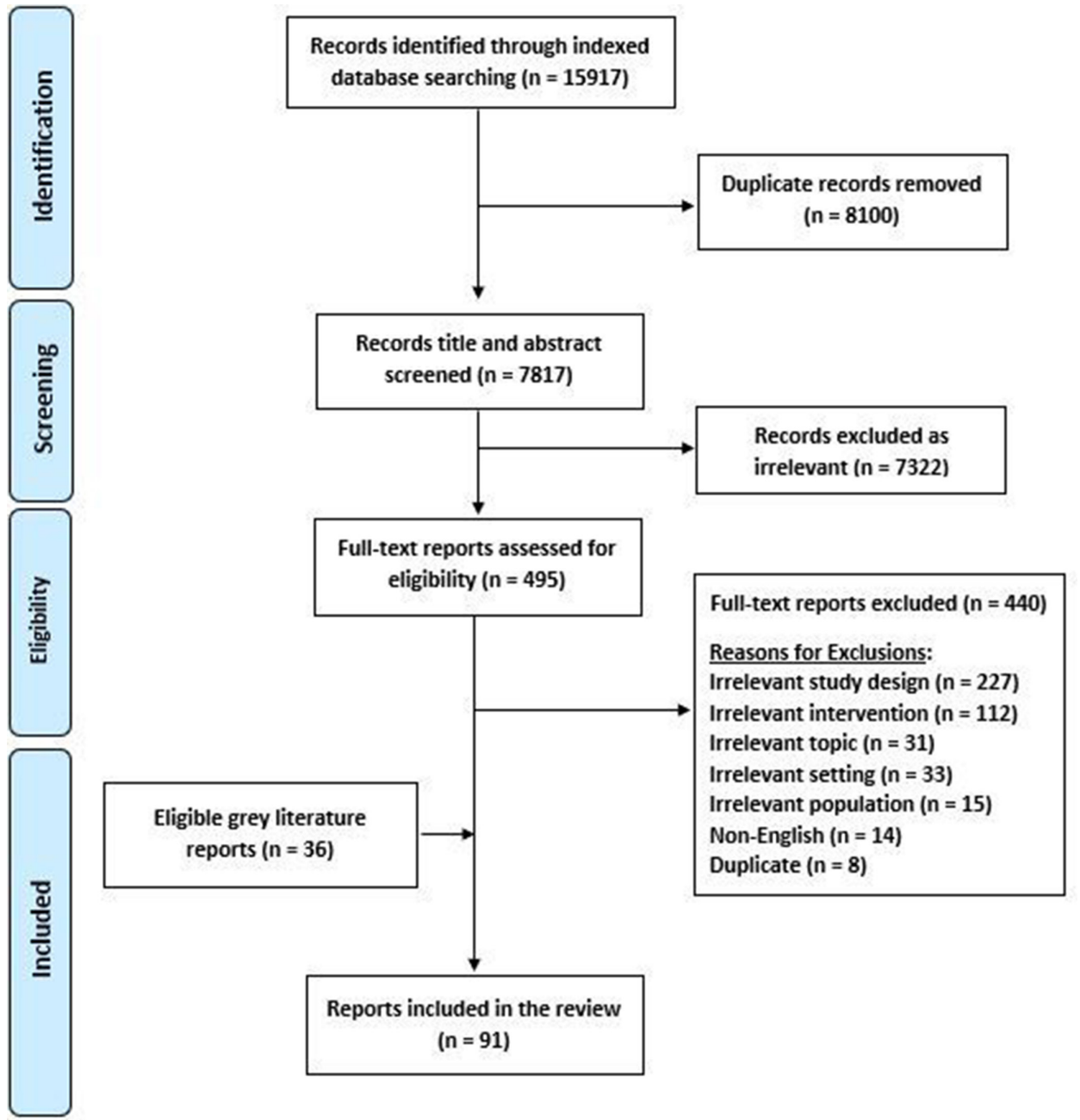

Figure 1 Preferred Reporting Items for Systematic Reviews and Meta-Analyses flow diagram.

\section{RESULTS}

\section{Characteristics of the included literature}

We retrieved a total of 7817 unique citations from our indexed database search, and ultimately assessed $55^{23-77}$ of these as eligible for the review (figure 1). An additional $36^{78-113}$ eligible publications were identified from the grey literature and from the reference lists of relevant systematic reviews, resulting in a total of 91 publications being included in this review (online supplemental appendix 3).

Nearly half of the included publications $(n=43,47 \%)$ reported on nutrition interventions delivered in conflictaffected countries in sub-Saharan Africa and about one-third $(n=31,34 \%)$ in the Middle East and North African region (table 1). The country-level distribution of the included publications is illustrated in figure 2 . Most publications $(\mathrm{n}=58,64 \%)$ reported on interventions targeting children under 5 years of age, while $30 \%(\mathrm{n}=27)$ reported on those targeting pregnant and lactating women. Refugee populations were the most targeted $(\mathrm{n}=53,58 \%)$, while about one-third reported on internally displaced persons (IDPs) $(\mathrm{n}=33,36 \%)$ and only about $16 \%(\mathrm{n}=15)$ reported on intervention delivery among those not displaced. Intervention delivery was reported to occur in camp settings in two-thirds $(\mathrm{n}=63$, $69 \%)$.

\section{Nutrition intervention delivery}

Figure 3 presents the relative frequency of the various nutrition interventions captured in the included literature. Nutrition-specific interventions were implemented either alone, or in combination with other nutritionspecific or nutrition-sensitive interventions or activities. General food distribution (GFD) was the most frequently reported intervention, followed by micronutrient supplementation, nutrition assessment, nutrition education, breast feeding and appropriate feeding, disease prevention and management, supplementary feeding, severe acute malnutrition/moderate acute malnutrition (SAM/ MAM) treatment, and food fortification.

We classified the individual interventions reported in the literature into broader categories, and we synthesise their components and delivery characteristics below.

\section{Nutrition assessment}

Twenty-six publications reported on mass screening for malnutrition as a component of other nutrition interventions. 232527293249515369737779838487889296 100-102 104 
Table 1 Characteristics of included publications $(n=91)$

\begin{tabular}{|c|c|}
\hline Geographic region* ${ }^{\star}$ & $\mathrm{n}$ \\
\hline East Asia and Pacific & 3 \\
\hline Europe and Central Asia & 5 \\
\hline Latin America and the Caribbean & 1 \\
\hline Middle East and North Africa & 31 \\
\hline Sub-Saharan Africa & 43 \\
\hline South Asia & 9 \\
\hline Publication type & n \\
\hline Non-research report & 53 \\
\hline Observational study & 32 \\
\hline Quasi-experimental study & 2 \\
\hline Randomised controlled trial & 4 \\
\hline Target population type ${ }^{\dagger}$ & $\mathbf{n}$ \\
\hline All/general population & 29 \\
\hline All women & 4 \\
\hline Women of reproductive age & 4 \\
\hline Pregnant and lactating women & 27 \\
\hline Adolescents & 10 \\
\hline Children under 5 years of age & 58 \\
\hline Displacement status of beneficiary population ${ }^{\dagger}$ & $\mathbf{n}$ \\
\hline Refugees & 53 \\
\hline IDPs & 33 \\
\hline Non displaced & 15 \\
\hline Returning refugees & 2 \\
\hline Host & 10 \\
\hline Unreported & 5 \\
\hline Setting of displaced population ${ }^{\dagger}$ & $\mathbf{n}$ \\
\hline Camp & 63 \\
\hline Dispersed & 45 \\
\hline Unreported & 2 \\
\hline
\end{tabular}

*World Bank regions.

†Individual publications may contribute to multiple categories.

107-109111 Of these, four were published between years 1990 and $2000,{ }^{2329} 3277$ one between 2001 and $2010^{51}$ and 21 between 2011 and 2018. 25274953697379838487889296 100-102 104 107-109 111 Ten studies conducted assessment in either hospitals or clinic or both, 2729328384101102104108109 nine studies conducted assessments in mobile clinics which were established by government, non-government organisations (NGO), and United Nations (UN) agencies, ${ }^{25} 474979878896100111$ four studies conducted assessment at home 235153107 and three studies failed to report on it. ${ }^{336977}$ Majority of the assessments were conducted at by NGO/UN staff.

Breastfeeding and appropriate infant and young child feeding We found 22 publications reporting on the delivery of interventions to promote or support breast feeding or other infant and young child feeding (IYCF) interventions. ${ }^{25} 28404347496465676878808386889298101104105$ 107110 Of these, five were published between years 2001 and 2010, ${ }^{2840646567}$ and 17 between 2011 and 2018. ${ }^{254347}$ 496878808386889298101104105107110 Most commonly, breast feeding was promoted using an outreach approach of home visits conducted by health workers within camp settings. 4964657898105107 In reports on nutrition intervention delivery in Pakistan, ${ }^{25}$ Jordan $^{92}$ and Somalia, ${ }^{88}$ mobile clinics were established by government and UN agencies in collaboration to promote breast feeding and sensitise refugee/internally displaced mothers on safe IYCF practices in and outside camp settings. Four publications reported on IYCF-related educational activities conducted among expectant/new mothers within hospital or clinic settings by community health workers (CHWs) or NGO/UN agency staff. ${ }^{40883104}$ In Macedonia, complementary foods were distributed through establishment of a food pipeline-a means to receive, store, and transport all donated food by multiple stakeholders. ${ }^{28}$ Among refugees and host populations in Jordan, the use of IYCF 'caravans" ${ }^{, 0}$ and 'safe havens ${ }^{\text {'110 }}$ set up by NGOs to provide safe spaces for mothers to breastfeed infants was reported, as well as the distribution of breastfeeding shawls to lactating mothers to provide privacy. ${ }^{80}$

\section{Disease prevention and management}

Twenty publications reported on the delivery of interventions to either prevent and/or manage communicable disease among children under 5 years of age. ${ }^{25} 26293234$ $4044464952536264-677376107108$ Of these, six were published between years 1990 and 2000, ${ }^{29} 3234446276$ nine between 2001 and 201025 $2640465264-67$ and five between 2011 and 2018. ${ }^{495373107108}$ Some were conducted along with supplementary feeding as a part of nutrition rehabilitation programmes among refugee or internally displaced children under 5 years of age residing in camps or dispersed among local host populations in conflict settings. ${ }^{25} 262932$ 3440 $4446495364-6676$ Seven publications reported on measles or cholera vaccination for children under-five in subSaharan African countries, ${ }^{29} 323453667376$ delivered mostly at clinics/feeding centres by government or NGO/UN health workers. In India, vaccination was conducted by NGO/UN health workers as part of a measles outbreak response, using an outreach approach. ${ }^{52}$ Only one publication reported treatment of pregnant refugee women in Rwanda for malaria during antenatal care at UN/NGO clinic. ${ }^{44}$ Only one publication reported on the delivery of oral rehydration solution or zinc by CHWs to malnourished children under-five with diarrhoea, in a field-based trial among Afghan refugees residing along the border camps. $^{62}$ Another publication reported on therapeutic treatment of diarrhoea in a hospital setting in Uganda among children under 2years old. ${ }^{108}$ Deworming was delivered to children from 12 to 59 months of age as a part of facility/community-based nutrition rehabilitation programmes implemented in camps for refugees and IDPs by government health workers in Nepal, Sri Lanka and Yemen. 2649107 


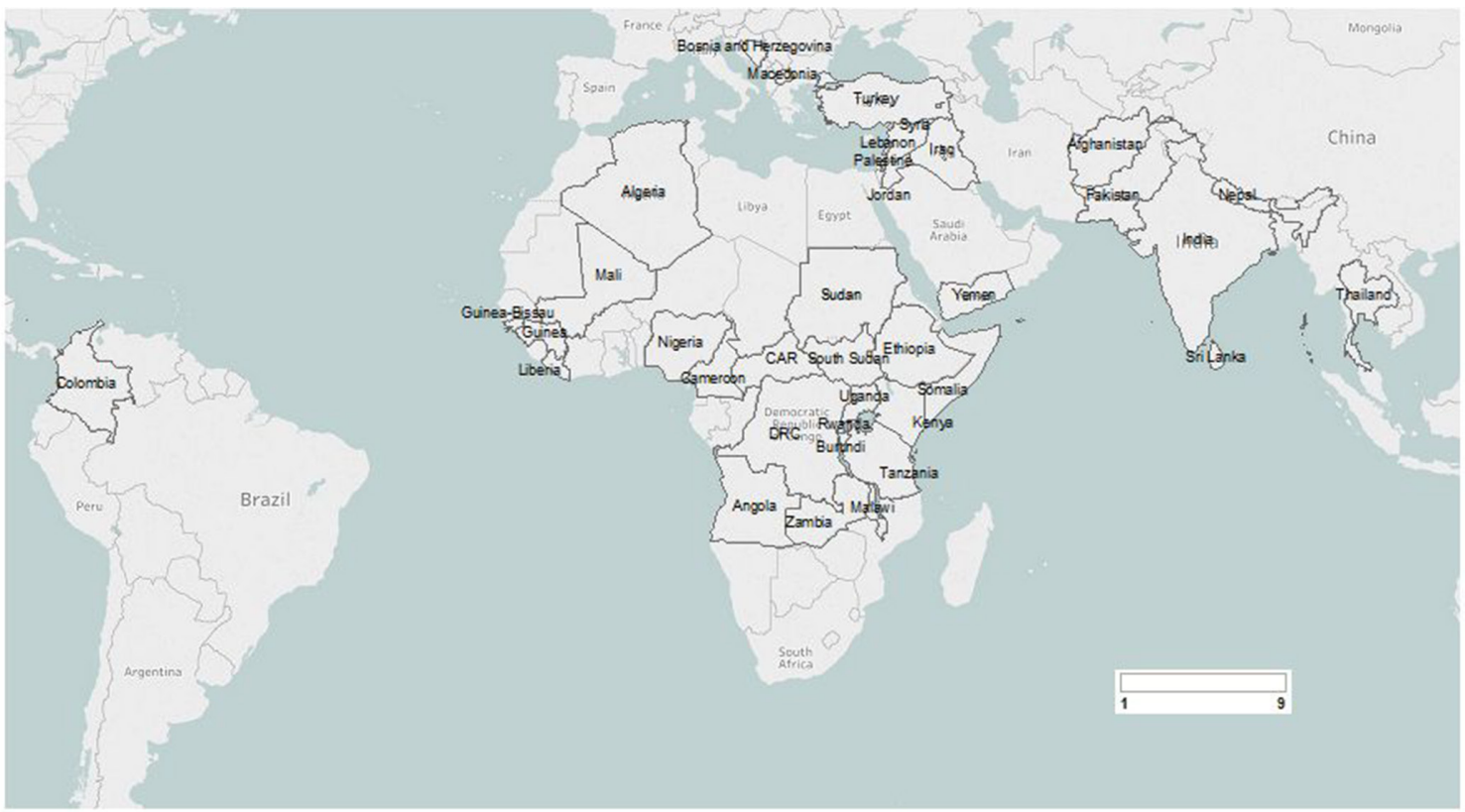

Figure 2 Geographic distribution of included publications.

\section{Food fortification}

Food fortification in conflict settings was not very commonly reported in the included literature. Only three publications reported on food fortification of which two were published between 2001 and $2010,{ }^{70} 75$ and one between 2011 and 2018. ${ }^{36}$ Two reported on locally produced and milled wheat or maize flour fortification, distributed by NGO/UN staff within the food baskets for camp-based refugees in Afghanistan and Democratic Republic of the Congo (DRG). ${ }^{70} 75$ One recently published research study in Palestine reported the implementation of a fortification programme in the West Bank and Gaza, but how such fortified foods were delivered to women, children or households was not described. ${ }^{36}$

\section{Micronutrient supplementation}

Twenty-seven publications reported on the delivery of micronutrient supplementation interventions to women or children in conflict settings. ${ }^{26} 30313436374044$ $4950525556585963-657172747983100101107108$ Of which five were published between years 1990 and 2000,3134445874 10 between 2001 and $2010^{37} 405255565964657279$ and 12 between years 2011 and 2018. 2630364950637183100101107108 Micronutrient supplementation in the form of powders was observed from year 2011 and onwards. ${ }^{26} 63107108$ We found six publications reporting iron and folic acid (IFA) supplementation being provided to pregnant or lactating women, among camp-based refugees or IDPs in Thailand ${ }^{30}{ }^{\text {Rwanda }}{ }^{44}$ Palestine,${ }^{56}$ Jordan,${ }^{79}$ Lebanon ${ }^{100}$ and Yemen. ${ }^{107}$ IFA supplementation was delivered as

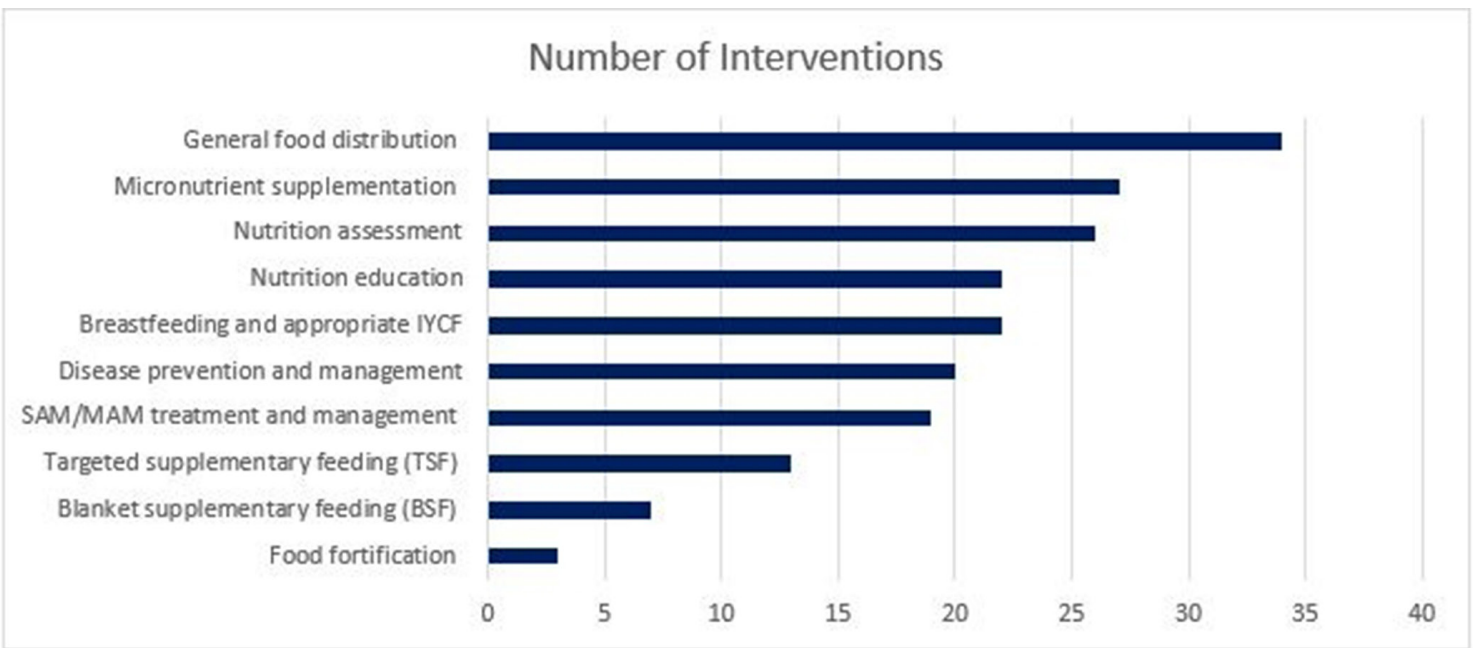

Figure 3 Reported nutrition interventions delivered to conflict-affected women and children. IYCF, infant and young child feeding. 
part of routine antenatal care by health workers in the community-based primary health clinic/mobile clinics run by NGOs and/or local government. Two publications reported on thiamine supplementation for pregnant women living in camps along the Thai-Burma border ${ }^{30}$ and visiting antenatal clinics of Shoklo Malaria Research Unit. ${ }^{59}$ In Tanzania, camp-based refugees were provided with stainless steel cooking pots at community-based distribution points in a study to evaluate their effectiveness in reducing iron deficiency anaemia. ${ }^{72}$

Vitamin A supplementation for non-displaced/IDP/ refugee children under-five living in West Bank and Gaza, ${ }^{36}{ }^{56}$ Guinea Bissau, ${ }^{59}{ }^{65} \mathrm{Nepal},{ }^{26}$ India $^{52}$ and Thailand $^{71}$ was reported in seven publications, sometimes delivered as a part of measles treatment protocol implemented at outreach level by health workers. ${ }^{52} 646571$ The delivery of multiple micronutrient (MMN) supplements for non-displaced/IDP/refugee women and children residing in Guinea Bissau, ${ }^{59}{ }^{64}$ Afghanistan, ${ }^{37}$ Malawi, ${ }^{58}$ Nepal, ${ }^{26}$ Lebanon, ${ }^{100}$ Uganda $^{108}$ and Yemen ${ }^{107}$ was reported in eight publications, distributed most commonly in powder, ready-to-use spread or cereal form through primary health centres or clinics. One publication reported on a randomised controlled trial in which pregnant women were provided with MMN tablets in Dadaab refugee camp in Kenya. ${ }^{50}$ Two publications reported on vitamin $\mathrm{C}$ supplementation interventions for refugee children in Ethiopia, ${ }^{31}$ and non-displaced children and adults in Afghanistan, ${ }^{37}$ although delivery modes were unreported. One publication reported on mass vitamin B complex supplementation provided to the general population by UN agencies in collaboration with local government as an emergency response to a pellagra outbreak in Malawi; where delivery site was unreported. ${ }^{58}$ Two publications reported on the delivery of micronutrient supplementation while providing nutrition rehabilitation through primary healthcare facilities to non-displaced children in Syria ${ }^{101}$ and refugee children in Lebanon. ${ }^{83}$

\section{General food distribution}

Thirty-four publications reported on GFD in conflict settings either through take home rations or hot cooked meal provision, or through cash or vouchers for food. ${ }^{23}$ 27-30 32 33 41-44 465455 57-5961636971 75 7781 82909193-9597106112113

Of these, eight were published between years 1990 and 2000, 2329323344545877 five between 2001 and 2010 284655 5975 and 21 between 2011 and 2018. ${ }^{27} 3041-435761636971$ $8182909193-9597106112113$ GFD in form of food vouchers/ cash assistance was given from the year 2011 onwards. ${ }^{27}$ 4143829195106112113 Four publications reported on specific food rations for pregnant women to meet extra nutrient requirements, ${ }^{30} 445971$ delivered by staff from UN agencies. Six publications reported on food distribution interventions targeted at children under-fiveyears of age, ${ }^{232731324664}$ and one targeted at women of reproductive age ${ }^{63}$ with food rations distributed at health centres, supplementary feeding centres or distribution points in the market. One publication reported on food rations delivered to everyone over the age of 15 years by NGO/ UN staff in Uganda, ${ }^{69}$ but the delivery mode was unreported.

In publications describing those GFD interventions where food rations were provided to households, the delivery personnel involved were either NGO staff ${ }^{284161}$ or were either not reported. ${ }^{32}$ In rural areas of northern Lebanon, community volunteers delivered hot meals multiple times per week to Syrian refugees through community kitchens. ${ }^{81}$ Two studies reported on delivering food rations to survivors of sexual and gender based violence, one study also provided 'safe shelter boundaries' during conflict to survivors of sexual and gender based violence. ${ }^{7894}$ Only one record was found where military personnel distributed food rations, in Iraq, but delivery mode was unreported. ${ }^{33}$

The provision of food through cash or voucher distribution was reported in 10 publications. ${ }^{27} 424382919597106$ 112113 These included IDPs or refugees living in camps/ dispersed settings in Lebanon, Turkey, Jordan, Syria, Central African Republic, Kenya and South Sudan and delivered by NGO/UN through print or electronic media (via mobile app/market-based ATMs) at homes/market/ NGO clinics.

\section{SAM/MAM treatment and management}

A total of 19 publications reported on interventions to treat acute malnutrition on an inpatient basis. ${ }^{24} 254049$ $606673798083858998100-102104109111$ Of these publications, only two were published between 2001 and 2010, ${ }^{406}$ and 17 between 2011 and 2018. 2425496073798083858998 100-102 104109111 All nutrition interventions were conducted by local Ministry of Health $(\mathrm{MOH})$ in collaboration with UN agencies/NGOs. The majority of the SAM treatment interventions included a combination of inpatient and community-based care of under-five children depending on the severity of malnutrition. ${ }^{25} 6673798385102104111$ SAM patients with complications were given inpatient care either in hospitals or therapeutic feeding centres, followed by provision of ready to use therapeutic food (RUTF), BP100 Plumpy nuts or F100 milk retrieved periodically from outpatient clinics in some cases, and onsite feeding at supplementary/outpatient therapeutic feeding centres in other cases. ${ }^{25} 4960668083$ One study reported on mixing of RUTF with nutrient dense product (NRG-5) with milk or juice to mask up the foul taste of RUTF. ${ }^{83}$ The four main elements of the community-based management of acute malnutrition (CMAM) programme were management of MAM, management of SAM, inpatient management for SAM with medical complications and community outreach. ${ }^{79} 85104$ The studies on CMAM programme were mostly published after the year 2015. In some conflict settings where pre-existing healthcare system was absent or unable to respond, temporary services and structures were established by UN agency/ NGOs such as inpatient stabilisation centres for IDPs in South Sudan. ${ }^{102}$ 
Supplementary feeding

Twenty publications reported on supplementary feeding of which three were published between years 1990 and $2000,{ }^{317476}$ four between 2001 and $2010^{37566465}$ and 13 between 2011 and 2018. ${ }^{264973798083899399101 ~} 102104109$ Seven included publications reported on the delivery of blanket supplementary feeding (BSF) interventions in conflict settings to prevent acute malnutrition. ${ }^{313749749399101}$ BSF was provided in addition to general food rations in three publications, ${ }^{37} 4993$ while one publication reported on distribution of healthy baked snacks as thyme rolls and almond muffins, ${ }^{99}$ and one more publication reported on blanket distribution of ready to use supplementary food (RUSF) to internally displaced under five children as well as postnatal mothers in Syria through community-based clinics. ${ }^{101}$ Nearly all BSF programmes targeted children aged 6-59 months, predominantly in camp settings, but two publications reported BSF targeted at school-aged refugee children residing outside of camps and from the host community, in Somalia ${ }^{93}$ and Lebanon. ${ }^{99}$

Thirteen included publications reported on targeted supplementary feeding (TSF) interventions, aimed at treating MAM and preventing SAM. ${ }^{26} 566465737679808389102$ 104109 TSF was provided as a part of programme ${ }^{102} 104$ or as a standalone provision of RUSF, ${ }^{83} 89$ fortified local food ${ }^{80}$ or Super Cereal Plus. ${ }^{80} 109$ Most TSF interventions also focused on children aged 6-59 months in camp settings.

The majority of both blanket and TSF interventions were delivered either in supplementary feeding centre (SFC), in health centres or at distribution points in markets, ${ }^{26} 31374956646576798083102$ mostly by CHWs and/or formal health workers, 263749566465737683104 or by NGO/ UN staff. 74809399101109

\section{Nutrition education}

Twenty two publications reported on nutrition-focused education delivered alone or as a component of other nutrition interventions in conflict settings. ${ }^{34} 373840435662$ 676880838689929899101104105107110111 Of these, two studies were published between years 1990 and $2000,{ }^{34} 62$ four between 2001 and $2010,,^{37405667}$ and 16 between 2011 and 2018. . $^{33} 6880838689929899101104105107110111$ The majority of education initiatives focused on infant formula use, IYCF practices, water, sanitation and hygiene (WASH) promotion or on continued feeding of children during illness. ${ }^{37}$ 40435662676880838689929899101104105107110111 One publication reported on educating women about infectious disease management among under-five children, ${ }^{34}$ and another on an emergency response during konzo outbreak where food safety-related education was provided. ${ }^{38}$ All nutrition education interventions were conducted in hospitals, health centres or NGO clinics by NGO staff, health workers or CHWs.

\section{Nutrition intervention coverage and effectiveness}

Only eight publications ${ }^{23264964737689100}$ reported on the coverage $^{2326496476}$ (table 2) or the effectiveness ${ }^{4964737689100}$ (table 3) of delivered nutrition interventions. Further 11 publications failed to report data on coverage and provided data in numbers only. ${ }^{34683868890-92102104106}$ Two publications reported on the outcomes of treatment programmes for SAM, reporting only on performance indicators from Yemen, and Lebanon based therapeutic feeding programmes. ${ }^{89} 100$ When we compared the results with Sphere recommendations, we found SFP conducted from March to September 1994 in Burundi based SFCs reported lower coverage $(29.6 \%)$ than the recommended $(>50 \%) .{ }^{76}$ The SAM treatment performance indicators also reported lower recovery rates $(66.8 \%)$ than the recommended $(>75 \%) \cdot{ }^{76}$ Defaulters were also noted higher in proportion $(29.2 \%)$ than the recommended $(<15 \%)$ in Burundi. ${ }^{76}$ The same SFP reported coverage in Liberia, and DRC more than the minimum standard. ${ }^{76}$ The Bandim health project and humanitarian assistance in Guinea Bissau during 1998 and 1999 treated SAM children through community, and outreach approach. ${ }^{64}$ They also achieved almost minimum coverage $(57 \%)$, and recovery rate $(59.9 \%)$, while the defaulters were reported higher than the minimum (32\%). ${ }^{64}$ Another reported coverage of similar programme in 1998 among refugees and nondisplaced residents of Guinea Bissau ${ }^{23}$ and showed $87 \%$ coverage among refugees and $91 \%$ among residents. ${ }^{23}$ The same study reported on food distribution, which reported higher coverage among refugees $(41 \%)$ as compared with non-displaced residents (16\%). ${ }^{23} \mathrm{~A}$ camp based BSF and MNS programme implemented during 2008 and 2010 in Nepal reported above minimum coverage ranged between $95 \%$ and $98 \%{ }^{26}$ A large scale community-based nutritional status assessment at mobile clinics during the Nutrition Rehabilitation Programme in Sri Lanka also achieved high coverage $(97.3 \%$ in camps; $86 \%$ in urban and rural areas) than the Sphere recommendations. ${ }^{49}$ This programme also reported higher recovery rate for SAM treatment using TSF alone (90\%) and in combination of RUTF $(94 \%)$ as compared with the treatment with only RUTF $(42.5 \%) .{ }^{49}$ All these three treatments when used to treat MAM children, recovery rates were noted lower ranged between $32 \%$ and $50 \%{ }^{49}$ When all three SAM treatments were compared, the proportion of defaulters were noted lowest $(0.9 \%)$ in the combined treatment with TSF and RUTF. ${ }^{49}$ The default rate for MAM treatment was unreported. ${ }^{49}$ Another large scale camp based feeding programme at SFCs in Tanzania and Kenya treated SAM children with recovery rates of $75 \%$, and $78 \%$, respectively. ${ }^{73}$ While the MAM recovery rates were reported as $76 \%$ in Tanzania, and 92\% in Kenya. ${ }^{73}$ Within Yemen based TFP, the increase in recovery rates and transfers to OTP was likely due to the improved quality of care brought about by the training programme. $^{89}$

\section{Barriers to and facilitators of nutrition intervention delivery}

Specific delivery barriers that we identified from the literature are presented in table 4 . Insufficient resources and ongoing insecurity were key barriers recurring in the literature. Multiple publications reported on supply shortages of important commodities, especially of RUTF 


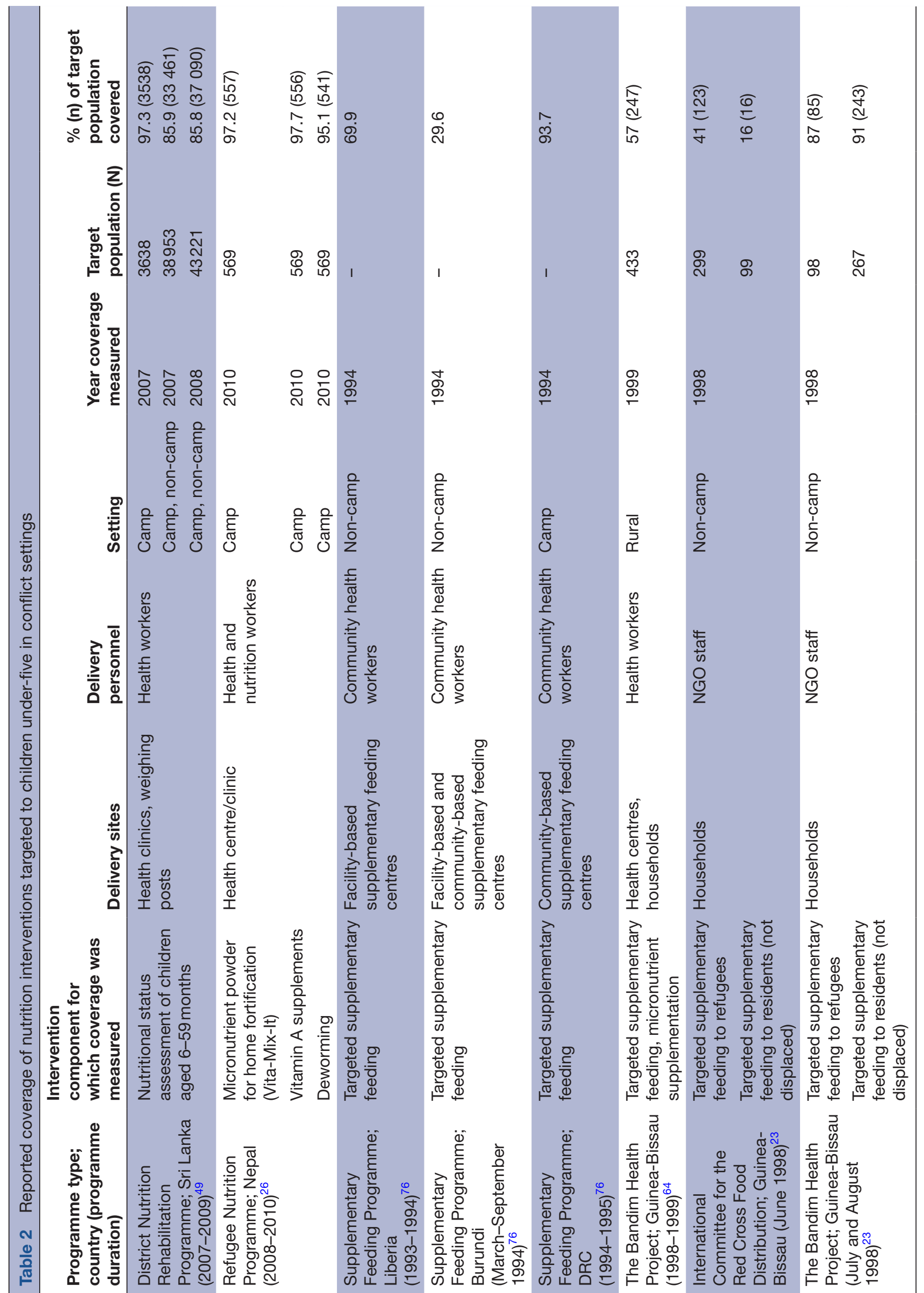

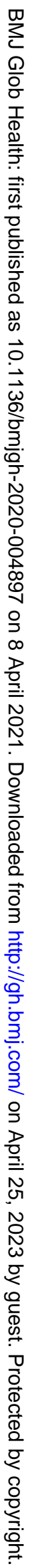




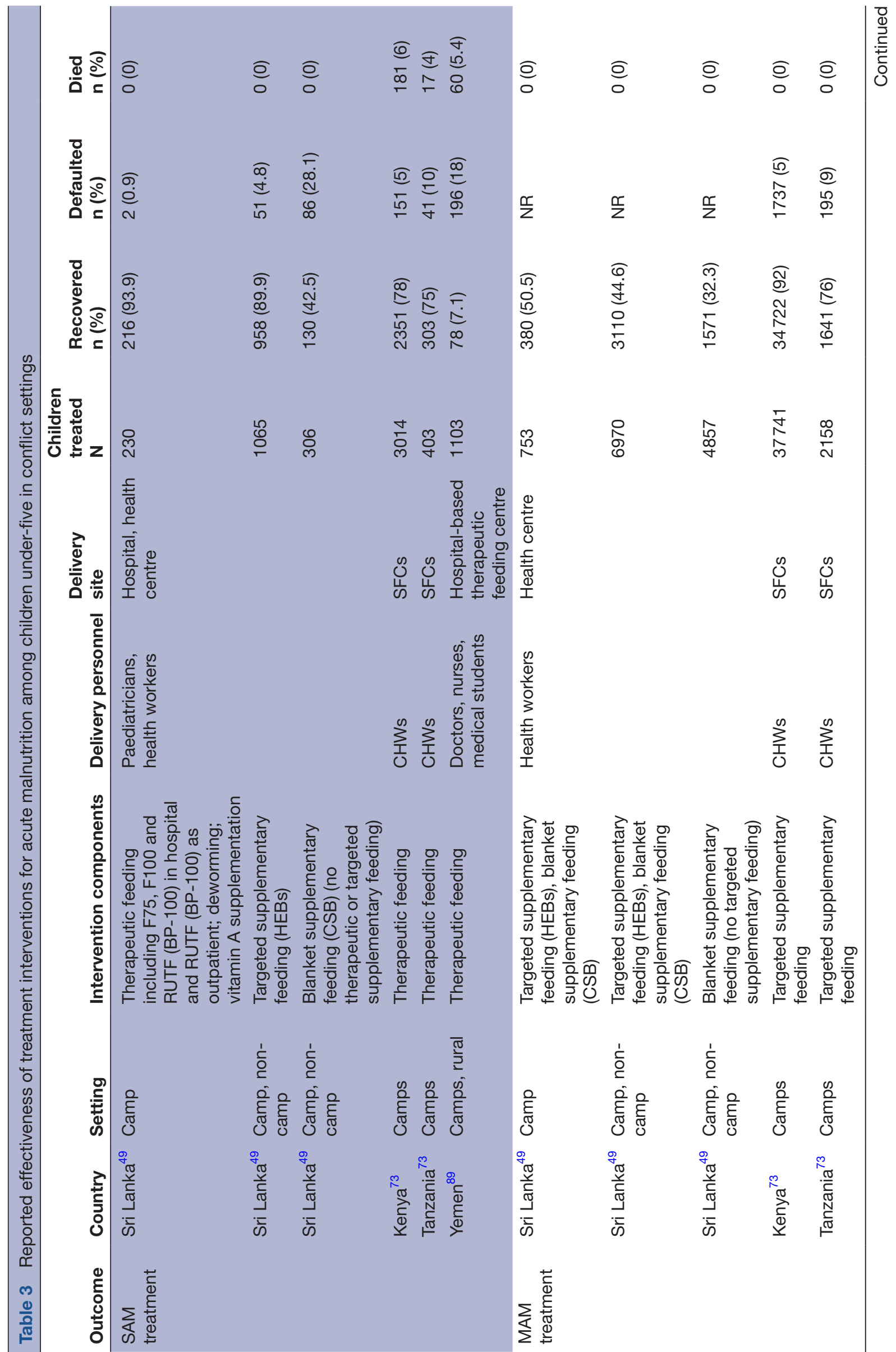

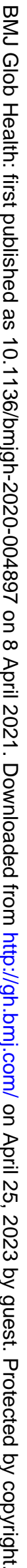




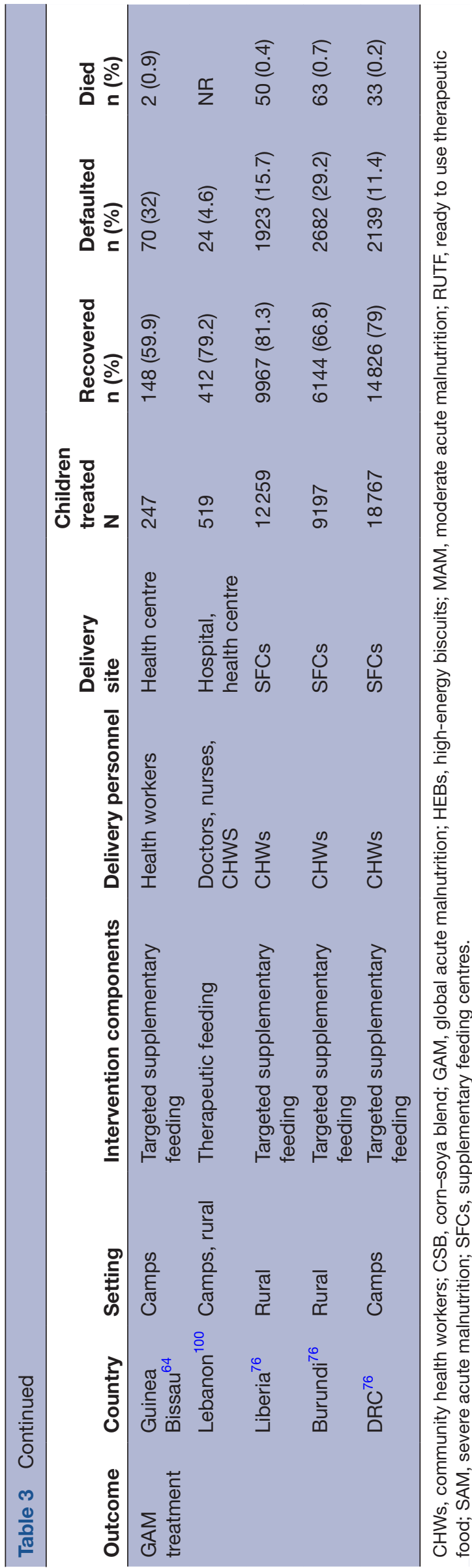

and micronutrient supplements, as well as insufficient human resources and limited funding. Humanitarian actors faced multiple security and accessibility issues due to ongoing conflict, collapsed healthcare systems, and damaged infrastructure, while limited inter-cluster coordination and lack of coordination between humanitarian partners posed additional delivery challenges. Population movements in and out of camps made it difficult to reach vulnerable populations and provide follow-up care. Gender bias and negative sociocultural practices (genital mutilation, early marriages, child labour) also hindered in intervention delivery. Outcome assessment by unskilled staff, security concerns, reporting errors, small sample size, and less rigorous methods resulted in poor reporting of coverage and effectiveness outcomes in the included studies.

Effective social mobilisation, monitoring and surveillance, and integration of nutrition services into other sectors were key delivery facilitators (table 4). Local community members, religious leaders and established community networks were leveraged to effectively deliver nutrition interventions. The establishment of nutrition surveillance systems was found to be effective in strengthening local monitoring systems. A multi-sectoral programming approach was reported in multiple instances, with the nutrition cluster collaborating with the health and WASH clusters to facilitate delivery of comprehensive nutrition-specific and sensitive interventions, and interventions being integrated into local healthcare systems. Some national-level programmes adopted evidencebased guidelines to scale up nutrition interventions through community-based approaches, especially for the acute malnutrition. There were several examples of intensive training and capacity building of workers, as well as task shifting, implemented to improve coverage of acute malnutrition and IYCF interventions.

\section{DISCUSSION}

We identified 91 publications from 1990 and 2018 that described the delivery of nutrition interventions to women and children affected by armed conflict in LMICs, mostly reported in African region. Less than half of the included publications reported on research findings, and nearly $40 \%$ were sourced from the grey literature. Studies published between year 1990 and 2000, majorly focused on GFD and disease prevention and management. Studies published between year 2001 and 2010 also focused on disease prevention and management and on micronutrient supplementation, and studies published after 2011 focused on nutrition assessment, GFD and SAM/MAM treatment. GFD, micronutrient supplementation and nutrition assessment were the most frequently reported interventions, with most publications reporting on intervention delivery to refugee populations in camp settings and using community-based approaches (figure 4). ${ }^{114}$ Limited data on intervention coverage or effectiveness were captured from the included literature, 


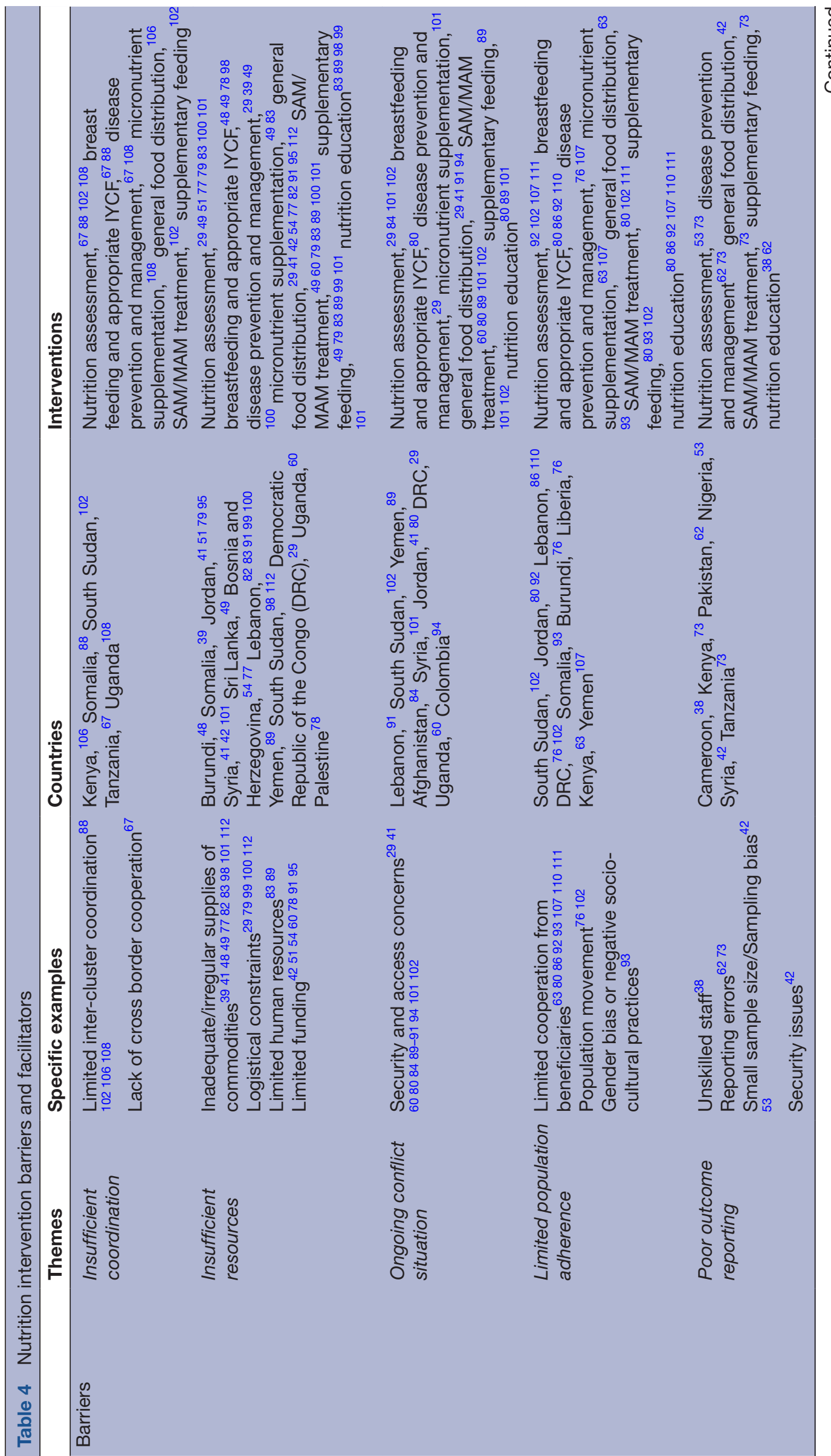




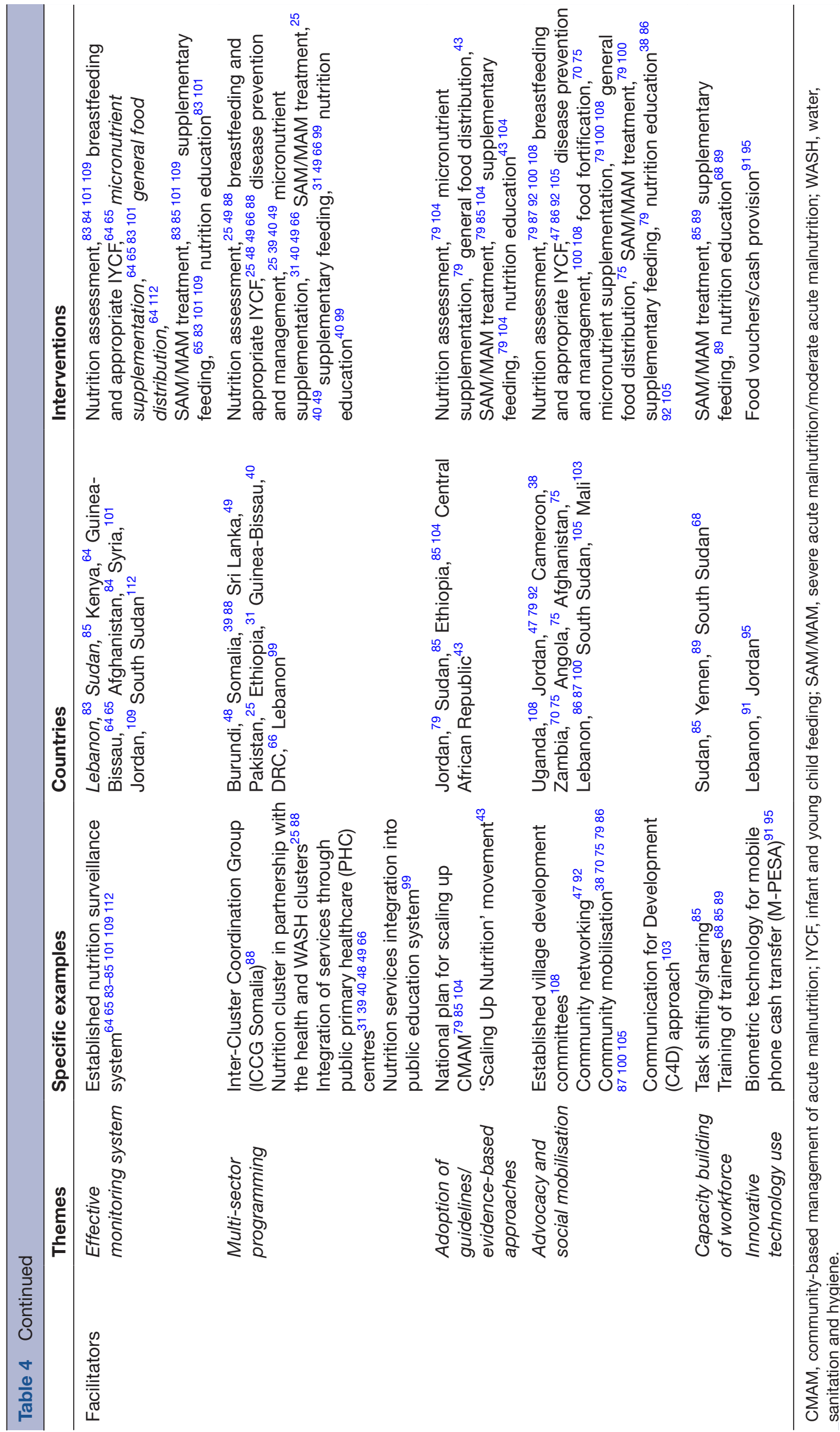




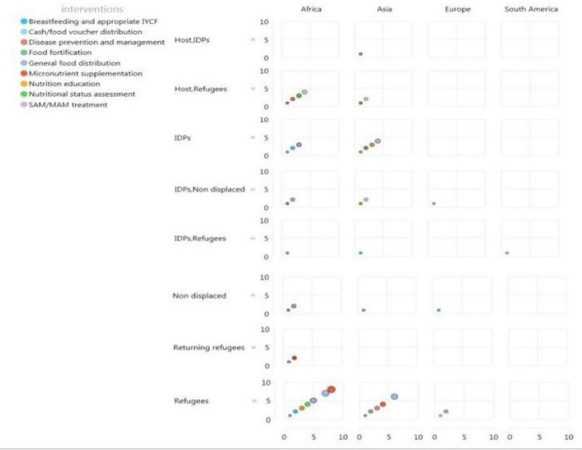

Figure 4 Summary of evidence. IDP, internally displaced person; IYCF, infant and young child feeding; SAM/MAM, severe acute malnutrition/moderate acute malnutrition.

preventing inferences to be drawn about how these vary by different delivery approaches in conflict settings. Very rarely were quantitative estimates reported, but delivery mechanisms and barriers and facilitators were more comprehensively described in the grey compared with the indexed literature. Insufficient resources, including nutritional commodity shortages, security concerns due to ongoing conflict, limited inter-cluster coordination, and difficulty accessing and following beneficiaries up due to population movements and sometimes limited cooperation were key delivery barriers. Community advocacy and social mobilisation, effective monitoring, and integration of nutrition and other sector interventions and services were key delivery facilitators.

Our results yield important insights about the nutrition delivery and important gaps. It is evident that much of the documentation of nutrition interventions and programmes implemented in conflict and likely in emergency settings more generally, exists in the grey literature generated by UN agencies, NGOs and other humanitarian implementers actively working in the field rather than from government reports and indexed literature. Second, the limited number of included studies and variation in population behaviour and in context such as country, underlying health system, disease outbreak, and type and severity of conflict has curtailed us from studying the impact of nutrition intervention on women in conflict setting in greater depth.

In addition, much of the literature focused on nutrition interventions delivered to camp-based refugees, with relatively little reported on populations displaced or nondisplaced populations. It is difficult to know whether the lack of reporting on non-camp and non-displaced populations reflects actual nutrition intervention delivery patterns on the ground, or rather a failure to document.

With respect to the types of interventions, the relatively higher frequency of reporting on food distribution and the management of acute malnutrition is understandable, given the high prevalence of food insecurity and the high morbidity and mortality burden of malnutrition. It was somewhat surprising to find relatively little on the delivery of IYCF interventions, though there were some examples of innovative practices to provide safe spaces for women to breast feed. Moreover, we captured just as many publications reporting on infant formula distribution as on breastfeeding promotion interventions.

We also found that many publications reported on nutrition intervention delivery at household level or through outreach approaches. We also note that the CMAM has been adopted as national policy by several governments including Ethiopia, Jordan and Sudan. Given these experiences, the humanitarian nutrition sector may be particularly well-placed to further innovate and test community-based approaches that might overcome or circumvent the specific implementation challenges across sectors.

In context to barriers of delivery; destruction of health facilities, targeted attacks on facilities and health workers, as well as disruption of supply chains were key issues, which further added to the existing weak governance and healthcare system infrastructure. Thus, the actors should identify effective strategies for delivering interventions through planning which must addresses the security concerns of health service providers and beneficiaries. Moreover, gathering support and acceptance from local influencers and communities, including local authorities, appears to be critical, while maintaining the perception of their impartiality and neutrality.

Finally, literature reports on multi-sectoral programming approach with the nutrition cluster collaborating with the health and WASH clusters, but has failed to report its integration with early childhood development and mental health, which is an emerging issue. Moreover, there is no data on gender equality and social inclusion. Thus, future studies should untake gender analyses, to investigate the gendered differences in access, needs and uptake of healthcare services.

This systematic review of the literature is the first, to our knowledge, to focus on the delivery of nutrition interventions in armed conflict settings, and thus makes a novel and important contribution to the field. However, in addition to the limitations inherent in the existing literature itself, discussed above, we must also acknowledge that by restricting our review only to publications published in English, and by undertaking a comprehensive but not exhaustive search of the grey literature, we have inevitably excluded other relevant publications that may have provided different information from what we have captured presently.

\section{CONCLUSION}

There is very little information on achieved coverage or effectiveness of nutrition interventions delivered in conflict settings; more (and more rigorous) evaluation of different delivery approaches is needed, including outside of camps and for preventive as well as curative nutrition interventions. The humanitarian nutrition sector may be particularly well-placed to advance the field with respect to community-based intervention delivery in conflict contexts, and has effective, existing networks to 
widely disseminate the important evidence that it could generate.

\section{Twitter Fahad J Siddiqui @fjsepi}

Contributors All authors contributed in writing this manuscript

Funding Aga Khan University has received funding from the Family Larsson Rosenquist Foundation. As coordinator of the Bridging Research \& Action in Conflict Settings for the Health of Women \& Children (BRANCH) Consortium, the SickKids Centre for Global Child Health has received funding for research activities from the International Development Research Centre (108416-002 and 108640-001), the Norwegian Agency for Development Cooperation (Norad) (QZA-16/0395), the Bill \& Melinda Gates Foundation (OPP1171560) and UNICEF (PCA 20181204).

Map disclaimer The depiction of boundaries on this map does not imply the expression of any opinion whatsoever on the part of BMJ (or any member of its group) concerning the legal status of any country, territory, jurisdiction or area or of its authorities. This map is provided without any warranty of any kind, either express or implied.

\section{Competing interests None declared.}

Patient consent for publication Not required.

Ethics approval Ethics approval was not required, as this paper is a systematic review of publically available, published literature.

Provenance and peer review Not commissioned; externally peer reviewed.

Data availability statement Data are available upon request. Data extracted from publications retrieved from the indexed and grey literature are available from the corresponding author upon reasonable request.

Supplemental material This content has been supplied by the author(s). It has not been vetted by BMJ Publishing Group Limited (BMJ) and may not have been peer-reviewed. Any opinions or recommendations discussed are solely those of the author(s) and are not endorsed by BMJ. BMJ disclaims all liability and responsibility arising from any reliance placed on the content. Where the content includes any translated material, BMJ does not warrant the accuracy and reliability of the translations (including but not limited to local regulations, clinical guidelines, terminology, drug names and drug dosages), and is not responsible for any error and/or omissions arising from translation and adaptation or otherwise.

Open access This is an open access article distributed in accordance with the Creative Commons Attribution 4.0 Unported (CC BY 4.0) license, which permits others to copy, redistribute, remix, transform and build upon this work for any purpose, provided the original work is properly cited, a link to the licence is given, and indication of whether changes were made. See: https://creativecommons.org/ licenses/by/4.0/.

ORCID iDs

Shailja Shah http://orcid.org/0000-0003-2329-5027

Zahra Ali Padhani http://orcid.org/0000-0003-4777-7565

Reena P Jain http://orcid.org/0000-0001-7004-5093

\section{REFERENCES}

1 Ploughshares P. Armed conflict 2016, 2018. Available: http:// ploughshares.ca/armed-conflict/defining-armed-conflict/

2 O'cathain A, Murphy E, Nicholl J. The quality of mixed methods studies in health services research. $J$ Health Serv Res Policy 2008;13:92-8.

3 World Health Organization. Communicable diseases and severe food shortage: who technical note, October 2010: World Health organization, 2010. Available: https://www.usaid.gov/global-health/ health-areas/nutrition/technical-areas/nutrition-emergenciestechnical-guidance-brief

4 OCHA. Global humanitarian overview United Nations Office for the Coordination of Humanitarian Affair; 2018. https://www.unocha. org/publication/global-humanitarian-overview/global-humanitarianoverview-2018 [Accessed 13 July 2019].

5 UNICEF. UNICEF's approach to scaling up nutrition United Nations Children's Fund (UNICEF). New York United Nations Children's Fund; 2015. https://sites.unicef.org/nutrition/files/Unicef_Nutrition_ Strategy.pdf [Accessed 20 August 2019].

6 Gaffey MF, Waldman RJ, Blanchet K, et al. Delivering health and nutrition interventions for women and children in different conflict contexts: a framework for decision making on what, when, and how. The Lancet 2021;397:543-54.

7 Blanchet K, Sistenich V, Ramesh A. An evidence review of research on health interventions in humanitarian crises. London: London School of Hygiene \& Tropical Medicine, Harvard School of Public Health, Overseas Development Institute, 2015.

8 Roberts B, Guy S, Sondorp E, et al. A basic package of health services for Post-Conflict countries: implications for sexual and reproductive health services. Reprod Health Matters 2008;16:57-64.

9 Sphere Association. The sphere Handbook: humanitarian charter and minimum standards in humanitarian response. Geneva, Switzerland Sphere Association; 2018. www.spherestandards.org/ handbook [Accessed 13 December 2019].

10 Hossain M, Choudhury N, Adib Binte Abdullah K, Abdullah K, et al. Evidence-Based approaches to childhood stunting in low and middle income countries: a systematic review. Arch Dis Child 2017;102:903-9.

11 Kamali M, Munyuzangabo M, Siddiqui FJ, et al. Delivering mental health and psychosocial support interventions to women and children in conflict settings: a systematic review. BMJ Glob Health 2020;5:e002014.

12 Munyuzangabo M, Khalifa DS, Gaffey MF, et al. Delivery of sexual and reproductive health interventions in conflict settings: a systematic review. BMJ Global Health 2020;5:e002206.

13 Aboubaker S, Evers ES, Kobeissi L, et al. The availability of global guidance for the promotion of women's, newborns', children's and adolescents' health and nutrition in conflicts. BMJ Glob Health 2020;5:e002060.

14 Als D, Meteke S, Stefopulos M, et al. Delivering water, sanitation and hygiene interventions to women and children in conflict settings: a systematic review. BMJ Glob Health 2020;5:e002064.

15 Jain RP, Meteke S, Gaffey MF, et al. Delivering trauma and rehabilitation interventions to women and children in conflict settings: a systematic review. BMJ Global Health 2020;5:e001980.

16 Meteke S, Stefopulos M, Als D, et al. Delivering infectious disease interventions to women and children in conflict settings: a systematic review. BMJ Global Health 2020;5:e001967.

17 Munyuzangabo M, Gaffey MF, Khalifa DS, et al. Delivering maternal and neonatal health interventions in conflict settings: a systematic review. BMJ Glob Health 2021;5:e003750 https://gh.bmj.com/content/5/Suppl_1/e003750 doi:10.1136/ bmjgh-2020-003750

18 Shah S, Munyuzangabo M, Gaffey MF, et al. Delivering noncommunicable disease interventions to women and children in conflict settings: a systematic review. BMJ Global Health 2020;5:e002047.

19 Moher D, Liberati A, Tetzlaff J, et al. Preferred reporting items for systematic reviews and meta-analyses: the prisma statement. PLoS Med 2009;6:e1000097.

20 Clarivate. Endnote [program]. Philadelphia, PA: Clarivate, 2013.

21 Khorram O, Khorram N, Momeni M, et al. Maternal undernutrition inhibits angiogenesis in the offspring: a potential mechanism of programmed hypertension. Am J Physiol Regul Integr Comp Physiol 2007;293:R745-53

22 Harris PA, Taylor R, Thielke R, et al. Research electronic data capture (REDCap)-A metadata-driven methodology and workflow process for providing translational research informatics support. $J$ Biomed Inform 2009;42:377-81.

23 Aaby P, Gomes J, Fernandes M, et al. Nutritional status and mortality of refugee and resident children in a non-cAMP setting during conflict: follow up study in Guinea-Bissau. BMJ 1999;319:878.

24 Altmann M, Suarez-Bustamante M, Soulier C, et al. First wave of the 2016-17 cholera outbreak in hodeidah city, Yemen - ACF experience and lessons learned. PLoS Curr 2017;9.

25 Bile KM, Hafeez A, Kazi GN, et al. Protecting the right to health of internally displaced mothers and children: the imperative of inter-cluster coordination for translating best practices into effective participatory action. East Mediterr Health J 2011;17:981-9.

26 Bilukha O, Howard C, Wilkinson C, et al. Effects of multimicronutrient home fortification on anemia and growth in Bhutanese refugee children. Food Nutr Bull 2011;32:264-76.

27 Bilukha O, Jayasekaran D, Burton A. Nutritional status of women and child refugees from Syria - Jordan, April-May 2014. Morbidity and Mortality Weekly Report 2014;63:638-9.

28 Borrel A, Taylor A, McGrath M, Hormann E, et al. From policy to practice: challenges in infant feeding in emergencies during the Balkan crisis. Disasters 2001;25:149-63.

29 Callaghan MP, Immerman B. Phs mission to Goma, Zaire. Public Health Rep 1995;110:95-9. 
30 Carrara VI SW, Lee SJ, et al. Longer exposure to a new refugee food ration is associated with reduced prevalence of small for gestational age: results from 2 cross-sectional surveys on the Thailand-Myanmar border. Am J Clin Nutr 2017;105:1382-90.

31 Centre for Disease Control. International notes update: Health and nutritional profile of refugees - Ethiopia, 1989-1990. Morbidity and Mortality Weekly Report 1990;39:707-18.

32 Centre for Disease Control. Health and nutritional status of Liberian refugee children, 1990. Weekly Epidemiological Record 1991;40:13-15.

33 Centre for Disease Control. Public health consequences of acute displacement of Iraqi Citizens-March-May 1991. JAMA 1991;266:633-4.

34 Centers for Disease Control and Prevention (CDC). Implementation of health initiatives during a cease-fire--Sudan, 1995. MMWR Morb Mortal Wkly Rep 1995;44:433-6.

35 Charchuk R, Houston S, Hawkes MT. Elevated prevalence of malnutrition and malaria among school-aged children and adolescents in war-ravaged South Sudan. Pathog Glob Health 2015;109:395-400.

36 Chaudhry AB, Hajat S, Rizkallah N, et al. Risk factors for vitamin $A$ and $D$ deficiencies among children under-five in the state of Palestine. Confl Health 2018;12:13.

37 Cheung E, Mutahar R, Assefa F, et al. An epidemic of scurvy in Afghanistan: assessment and response. Food Nutr Bull 2003;24:247-55.

38 Ciglenečki I, Eyema R, Kabanda C, et al. Konzo outbreak among refugees from central African Republic in eastern region, Cameroon. Food and Chemical Toxicology 2011;49:579-82.

39 Collins S, Myatt M, Golden B. Dietary treatment of severe malnutrition in adults. Am J Clin Nutr 1998;68:193-9.

40 Colombatti R, Coin A, Bestagini P, et al. A short-term intervention for the treatment of severe malnutrition in a post-conflict country: results of a survey in guinea Bissau. Public Health Nutr 2008;11:1357-64.

41 Doocy S, Sirois A, Anderson J, et al. Food security and humanitarian assistance among displaced Iraqi populations in Jordan and Syria. Soc Sci Med 2011;72:273-82.

42 Doocy S, Tappis H, Lyles E, et al. Emergency food assistance in northern Syria: an evaluation of transfer programs in Idleb Governorate. Food Nutr Bull 2017;38:240-59.

43 Dozio E, Peyre L, Morel SO, et al. Integrated psychosocial and food security approach in an emergency context. Intervention 2016;14:257-71.

44 Duckett J. Guidelines for dietary supplementation of pregnant women in a Rwandan refugee cAMP. J R Army Med Corps 1996;142:13-14

45 Dzumhur Z, Zec S, Buljina A, et al. Therapeutic feeding in Sarajevo during the war. Eur J Clin Nutr 1995;49 Suppl 2:S40-2.

46 Eltom AA. Internally displaced people-refugees in their own country. The Lancet 2001;358:1544-5.

47 Fander G, Beck N, Johan H, et al. PS-319a xtremely low exclusive breast feeding (EBF) rate among the Syrian refugee communities In Jordan. Arch Dis Child 2014;99:A226.2-A226.

48 Fournier AS, Mason F, Peacocke B, et al. The management of severe malnutrition in Burundi: an NGO's perspective of the practical constraints to effective emergency and medium-term programmes. Disasters 1999;23:343-9.

49 Jayatissa R, Bekele A, Kethiswaran A, et al. Community-Based management of severe and moderate acute malnutrition during emergencies in Sri Lanka: challenges of implementation. Food Nutr Bull 2012;33:251-60.

50 Kassim IAR, Ruth LJ, Creeke PI, et al. Excessive iodine intake during pregnancy in Somali refugees. Matern Child Nutr 2012;8:49-56.

51 Khatib IM, Samrah SM, Zghol FM. Nutritional interventions in refugee camps on Jordan's eastern border: assessment of status of vulnerable groups. East Mediterr Health J 2010;16:187-93.

52 Kumar V, Chaudhury L, Rathore R. An epidemiological analysis of outbreak of measles in a medical relief cAMP. Health and Population-Perspectives and Issues 2003:26:135-40.

53 Leidman E, Tromble E, Yermina A, et al. Acute malnutrition among children, mortality, and humanitarian interventions in conflictaffected regions - Nigeria, October 2016-March 2017. MMWR Morb Mortal Wkly Rep 2017;66:1332-5.

54 Leus X. Humanitarian assistance: technical assessment and public health support for coordinated relief in the former Yugoslavia. World Health Statistics Quarterly 1993;46:199-203.

55 Lopriore C, Guidoum Y, Briend A, et al. Spread fortified with vitamins and minerals induces catch-up growth and eradicates severe anemia in stunted refugee children aged 3-6 Y. Am J Clin Nutr 2004:80:973-81.
56 Magoni M, Jaber M, Piera R. Fighting anaemia and malnutrition in Hebron (Palestine): impact evaluation of a humanitarian project. Acta Trop 2008;105:242-8.

57 Mahomed Z, Moolla M, Motara F, et al. A Somalia mission experience. S Afr Med J 2012;102:659.

58 Malfait $P$, Moren A, Malenga G. Outbreak of pellagra among Mozambican refugees - Malawi, 1990. Morbidity and Mortality Weekly Report 1991;40:209-13.

59 McGready R, Simpson JA, Cho T, et al. Postpartum thiamine deficiency in a Karen displaced population. Am J Clin Nutr 2001;74:808-13.

60 Morris J, Jones L, Berrino A, et al. Does combining infant stimulation with emergency feeding improve psychosocial outcomes for displaced mothers and babies? A controlled evaluation from Northern Uganda. Am J Orthopsychiatry 2012;82:349-57.

61 Morseth MS, Grewal NK, Kaasa IS, et al. Dietary diversity is related to socioeconomic status among adult Saharawi refugees living in Algeria. BMC Public Health 2017;17:621.

62 Murphy $\mathrm{HH}$, Bari A, Molla AM, et al. A field trial of wheat-based ora rehydration solution among Afghan refugee children. Acta Paediatr 1996;85:151-7.

63 Ndemwa P, Klotz CL, Mwaniki D, et al. Relationship of the availability of micronutrient powder with iron status and hemoglobin among women and children in the Kakuma refugee cAMP, Kenya. Food Nutr Bull 2011;32:286-91.

64 Nielsen J, Valentiner-Branth P, Martins C, et al. Malnourished children and supplementary feeding during the war emergency in Guinea-Bissau in 1998-1999. Am J Clin Nutr 2004;80:1036-42.

65 Nielsen J, Benn CS, Balé C, et al. Vitamin A supplementation during war-emergency in Guinea-Bissau 1998-1999. Acta Trop 2005;93:275-82.

66 Renzaho A, Renzaho C. In the shadow of the volcanoes: the impact of intervention on the nutrition and health status of Rwandan refugee children in Zaire two years on fromthe exodus. Nutrition \& Dietetics 2003;60:85-91.

67 Rutta E, Gongo R, Mwansasu A, et al. Prevention of mother-tochild transmission of HIV in a refugee cAMP setting in Tanzania. Glob Public Health 2008;3:62-76.

68 Sami S, Kerber K, Tomczyk B, et al. "You have to take action": changing knowledge and attitudes towards newborn care practices during crisis in South Sudan. Reprod Health Matters 2017;25:124-39.

69 Schramm S. Nutritional status among adults in a post-conflict area Northern Uganda: are humanitarian assistance programmes creating disparities in health? Eur J Epidemiol 2013;28:S182.

70 Seal A, Kafwembe E, Kassim IAR, et al. Maize meal fortification is associated with improved vitamin $A$ and iron status in adolescents and reduced childhood anaemia in a food aid-dependent refugee population. Public Health Nutr 2008;11:720-8.

71 Stuetz W, Carrara V, Mc Gready R, et al. Impact of food rations and supplements on micronutrient status by trimester of pregnancy: cross-sectional studies in the Maela refugee cAMP in Thailand. Nutrients 2016;8:66.

72 Talley L, Woodruff BA, Seal A, et al. Evaluation of the effectiveness of stainless steel cooking pots in reducing iron-deficiency anaemia in food aid-dependent populations. Public Health Nutr 2010;13:107-15.

73 Tappis H, Doocy S, Haskew C, et al. United nations high commissioner for refugees feeding program performance in Kenya and Tanzania: a retrospective analysis of routine health information system data. Food Nutr Bull 2012;33:150-60.

74 Toole MJ, Bhatia R. A case study of Somali refugees in Hartisheik a cAMP, eastern Ethiopia: health and nutrition profile, July 1988-June 1990. J Refug Stud 1992;5:313-26.

75 van den Briel T, Cheung E, Zewari J, et al. Fortifying food in the field to boost nutrition: case studies from Afghanistan, Angola, and Zambia. Food Nutr Bull 2007;28:353-64.

76 Vautier F, Hildebrand K, Dedeurwaeder M, et al. Dry supplementary feeding programmes: an effective short-term strategy in food crisis situations. Tropical Medicine and International Health 1999;4:875-9.

77 Watson F, Kulenovic I, Vespa J. Nutritional status and food securtiy: winter nutrition monitoring in Sarajevo1993-1994. European Journal of Clinical Nutrition 1995;49:S23-32.

78 Abdulsalam W, Masri L. Ex-Post evaluation of UNICEF humanitarian action for children 2014-2015 in the state of Palestine UNICEF; 2016. https://www.unicef.org/evaldatabase/files/Ex-Post Evaluation_of_UNICEF_Humanitarian_Action_for_Children_20142015_in_the_State_of_Palestine.pdf [Äccessed 29 May 2019].

79 Abu-Taleb R. Experiences of emergency nutrition programming in Jordan. Field Exchange 2015;48:93. 
80 Alsamman S. Managing infant and young child feeding in refugee camps in Jordan. Field Exchange 2014;48:85.

81 Barakat J. Community kitchens in Lebanon: cooking together for health. Nutrition Exchange 2017:8:9.

82 Battistin F. Impact evaluation of the multipurpose cash assistance programme Beirut: Lebanon Cash Consortium; 2016. https:// reliefweb.int/sites/reliefweb.int/files/resources/LCCImpactEvaluat ionforMCAFebruary2016FINAL.PDF [Accessed 9 May 2019].

83 Berbari L, Ousta D, Asfahani F. Institutionalising acute malnutrition treatment in Lebanon. Field Exchange 2014;48:17.

84 Chinjekure A, Shams DM, Qureshi DA. Screening for materna and child malnutrition using sentinel-based national nutrition surveillance in Afghanistan. Field Exchange 2018;58:79.

85 Daniel T, Mekkawi T, Garelnabi H. Scaling up CMAM in protracted emergencies and low resource settings: experiences from Sudan. Field Exchange 2016;55:74.

86 Darjani P, Berbari L. Infant and young child feeding support in Lebanon: $\backslash$ strengthening the national system. Field Exchange 2014;48:20

87 Davidson J, Bethke C. Integrating community-based nutrition awareness into the Syrian refugee response in Lebanon. Field Exchange 2015;48:29.

88 Desie S. Somalia nutrition cluster: integrated famine prevention package. Field Exchange 2017:53-5.

89 Dureab F, Jawaldeh DA, Abbas DL. Building capacity in inpatient treatment of severe acute malnutrition in Yemen. Field Exchange 2016;55:87

90 Egendal R, Badejo A. WFP's emergency programme in Syria. Field Exchange 2015;48:113.

91 El-Huni E. WFP e-voucher programme in Lebanon. Field Exchange 2015;48:36

92 Fänder G, Frega M. Responding to nutrition gaps in Jordan in the Syrian refugee crisis: infant and young child feeding education and malnutrition treatment. Field Exchange 2014;48:82.

93 Farah Al. School feeding: experiences from Somalia. Nutrition Exchange 2014;4:17.

94 Feldman S, Freccero J, Seelinger K. Safe Haven: Sheltering displaced persons from sexual and gender-based violence. Case study: Colombia. Geneva Human Rights Center, University of California, Berkeley, in conjunction with the UN High Commissione for Refugees; 2013. https://reliefweb.int/report/world/safe-havensheltering-displaced-persons-sexual-and-gender-based-violence [Accessed 10 May 2019].

95 Giordano DK, Dunlop K, Gabay T, Sardiwal D. Evaluation synthesis of UNHCR's cash based interventions in Jordan United Nations High Commissioner for Refugees (UNHCR); 2017. https://www. unhcr.org/5a5e16607.pdf [Accessed 12 May 2019].

96 Hoetjes M, Rhymer W, Matasci-Phelippeau L. Emerging cases of malnutrition amongst IDPs in TAL Abyad district, Syria. Field Exchange 2015;48:133.

97 Inglis K, Vargas J. Experiences of the e-Food card programme in the Turkish refugee camps. Field Exchange 2014;48:145.

98 Kozuki N, Van Boetzelaer E, Zhou A, Tesfai C. Enabling treatment of severe acute malnutrition in the community: study of a simplified algorithm and tools in South Sudan International Rescue
Committee; 2018. https://www.rescue.org/report/enablingtreatment-severe-acute-malnutrition-community-study-simplifiedalgorithm-and-tools [Accessed 20 June 2020].

99 Karagueuzian N. Healthy snacks and nutrition education: School feeding in Lebanon's public schools. Nutrition Exchange 2017;8:10.

100 Karimova J, Hammoud J. Relief international nutrition and health programme in Lebanon. Field Exchange 2014;48:27.

101 Khudari H, Bozo M, Hoff E. Who response to malnutrition in Syria: a focus on surveillance, case detection and clinical management. Field Exchange 2015;48:118.

102 Laker M, Toose J. Nutrition programming in conflict settings: lessons from South Sudan. Field Exchange 2016;53:2.

103 Leonardi E, Arqués R. Real time evaluation of UNICEF's response to the Mali crisis United Nations Children's Fund (UNICEF); 2013. https://www.alnap.org/help-library/2013-mali-real-time-evaluationof-unicef\%E2\%80\%99s-response-to-the-mali-crisis [Accessed 27 April 2019].

104 Murphy M, Abebe K, O'Mahony S. Management of acute malnutrition in infants less than six months in a South Sudanese refugee population in Ethiopia. Field Exchange 2017;55:70.

105 Ndungu P, Tanaka J. Using care groups in emergencies in South Sudan. Field Exchange 2017;54:95-7.

106 O'Mahony A, MacAuslan I. Evaluation of post 2007 election violence recovery programme in Kenya. Field Exchange 2013;46:65.

107 Sallam DF, Albably K, Zvandaziva C. Community engagement through local leadership: increasing access to nutrition services in a conflict setting in Yemen increasing access to nutrition services in a conflict setting in Yemen. Nutrition Exchange 2018;9:10 https:// www.ennonline.net/nex/9nutserviceaccessyemen

108 Salse N, Salse N, Swarthout T, Xavier KF, Matsumoto A, Zahm C James K, Grace OE, Palma P, De Clerck V, Casademont C, Roll S, Benassconi A. Effectiveness of nutritional supplementation (readyto-use therapeutic food and multi micronutrient) in preventing malnutrition in children 6-59 months with infection (malaria, pneumonia, diarrhoea) in Uganda27 April 201927 April 2019 MSF OCA; 2013. https://fieldresearch.msf.org/handle/10144/559079? show=fullhttps://fieldresearch.msf.org/handle/10144/559079? show=full [Accessed 27 April 2019].

109 Sebuliba H, El-Zubi F. Meeting Syrian refugee children and women nutritional needs in Jordan. Field Exchange 2015;48:74.

110 Seguin J. Challenges of IYCF and psychosocial support in Lebanon. Field Exchange 2014;48:24.

111 Tchamba A. Alert and rapid response to nutritional crisis in DRC. Field Exchange 2017;54:3.

112 Van Der Merwe R. Impact of milling vouchers on household food security in South Sudan. Field Exchange 2014;47:7.

113 Yunusu E, Markhan M. Cash-based programming to address hunger in conflict-affected South Sudan: a case study. South Sudan World Vision; 2016. https://www.wvi.org/sites/default/files/ World\%20Vision\%20Case\%20Study\%20South\%20Sudan_cash. pdf [Accessed 18 May 2019].

114 Carroll GJ, Lama SD, Martinez-Brockman JL, et al. Evaluation of nutrition interventions in children in conflict zones: a narrative review. Adv Nutr 2017;8:770-9. 